\title{
O ciclo da vesícula sináptica, espinhos dendríticos e a transdução de sinal*
}

\section{Synaptic vesicle cycle, dendritic spines and signal transduction}

\author{
Suélen Merloํㄹ Janaína Brusco², Fernando E. Padovan-Neto², Carlos J. S. Rohner ${ }^{1}$, Érika T. Ikeda ${ }^{3}$, Jana B. de \\ Ross $^{1}$, Lezio S. Bueno Júnior ${ }^{2}$, Rafael N. Ruggiero ${ }^{1}$, Helene A Fachim ${ }^{4}$, e Jorge E. Moreira ${ }^{5}$
}

\begin{abstract}
RESUMO:
No sistema nervoso, a sinapse é a estrutura que permite a um neurônio passar um sinal elétrico ou químico a outro neurônio ou outra célula (muscular ou glandular). A palavra sinapse vem de "synaptein", palavra que Sir Charles Scott Sherrington e seus colegas acunharam do grego "syn" (junto) e "haptein" (afivelar). As sinapses podem ser separadas entre elétricas e químicas, porém a maior parte da transmissão sináptica é realizada através das sinapses químicas. Apesar das sinapses químicas terem uma resposta mais lenta que as elétricas, elas possuem a vantagem da amplificação do sinal gerada através de uma cascata de segundos mensageiros. As sinapses químicas podem ser excitatórias ou inibitórias e são caracterizadas por um terminal pré-sináptico (onde estão presentes as vesículas que contêm os neurotransmissores) em contato com um terminal pós-sináptico (onde estão presentes os receptores ionotrópicos e metabotrópicos para esses neurotransmissores) separados pela fenda sináptica. As sinapses típicas acontecem sobre axônios (axo-axônicas), sobre dendritos (axo-dendríticas), sobre o soma de outro neurônio (axo-somáticas) e sobre os espinhos dendríticos. Os espinhos dendríticos são pequenas profusões da membrana celular especializadas na compartimentalização sináptica. Atualmente há muita informação sobre a biossíntese dos neurotransmissores clássicos como acetilcolina, glutamato, GABA, glicina, dopamina, noradrenalina e serotonina e os seus receptores específicos para o funcionamento do sistema nervoso central (SNC). Ao mesmo tempo o estudo de novas substâncias neurotransmissoras (por exemplo ATP, óxido nítrico, endocanabinóides e neuropeptídeos) tem avançado enormemente. Esta revisão é uma seleção resumida de informações fundamentais a partir da literatura mais recente dos principais aspectos funcionais e moleculares do ciclo da vesícula sináptica, da composição da densidade pós-sináptica, dos espinhos dendríticos e do mecanismo de transdução de sinal.
\end{abstract}

Palavras-chave: Transmissão Sináptica. Proteínas Sinápticas. Receptores, Neurotransmissores.

${ }^{1}$ Mestrandos e ${ }^{2}$ Doutorandos do Programa de Pós-Graduação em Neurologia/Neurociências, Departamento de Neurociências e Ciências do Comportamento, Faculdade de Medicina de Ribeirão Preto (FMRP-USP).

${ }^{3}$ Graduanda do Curso de Fisioterapia, (FMRP-USP).

${ }^{4}$ Doutoranda do Programa de Pós-Graduação em Psicobiologia, Departamento de Biologia, Faculdade de Filosofia, Ciências e Letras de Ribeirão Preto.

${ }^{5}$ Professor da disciplina RNP 5767, "Aspectos Moleculares da Liberação Sináptica", do Programa de Pós Graduação em Neurologia/Neurociências; Laboratório de Estrutura Sináptica, Departamento de Biologia Celular e Molecular e Bioagentes Patogênicos, FMRP USP.
Correspondência: Prof. Dr. Jorge E. Moreira, cello@fmrp.usp.br Departamento de Biologia Celular e Molecular e Bioagentes Patogênicos - FMRP/USP Avenida Bandeirantes, 3900 14049-900 - Ribeirão Preto, SP Telefone 36023284.

Artigo recebido em 29/10/2010 Aprovado para publicação em 10/06/2011

* Resultados de seminários e discussões realizados durante o curso RMF 5767, entre 26 de outubro a 26 de novembro de 2009. 


\section{Introdução}

Desde que se reconheceu que o sistema nervoso é constituído de células distintas ${ }^{1,2}$ e de que Ramón y Cajal em 1888 propôs a teoria neurona ${ }^{1,3}$, que forma atualmente o verdadeiro miolo da neurociência, tornou-se inevitável supor que os neurônios tinham de estar conectados de algum modo para que as informações em forma de potencial elétrico que cada um deles gerasse ou recebesse pudessem ser transmitidas a outras células. Esse local de contato foi definido como sinapse. A hipótese seminal da sinapse química foi demonstrada por Brock e colaboradores em 1952. ${ }^{4}$ As sinapses elétricas no sistema nervoso central (SNC) dos vertebrados foram descritas somente em 2004 por Bennett e Zukin. ${ }^{5}$

As sinapses são essenciais para a função neuronal. Numa sinapse a membrana plasmática do neurônio pré-sináptico se sobrepõe apertadamente com a membrana do neurônio pós-sináptico. Ambos os sítios pré e pós-sináptico contêm um arranjo extensivo de uma maquinaria molecular que junta ambas membranas e produz o processo de sinalização. ${ }^{6}$

As sinapses elétricas possuem a estrutura das junções comunicantes (junções GAP) de outros sistemas, essas junções são regiões de aproximação entre duas células, contendo em suas membranas canais iônicos, que podem se acoplar e formar poros responsáveis por difundir os íons e também grandes molécu- las como a adenosina tri-fosfato (ATP) e segundos mensageiros. A transmissão da corrente iônica ocorre passivamente de um neurônio para outro devido à diferença de potencial gerada localmente pelo potencial de ação (PA), sinal que se propaga de um ponto inicial no corpo neuronal (chamado cone de implantação) até o terminal axonal. Essa transmissão é bidirecional e extraordinariamente rápida. $5,7,8$

As sinapses químicas, por sua vez, apresentam um terminal pré-sináptico (onde é gerado o PA) e um pós-sináptico (onde são gerados os efeitos do PA) com um espaço maior entre eles chamado de fenda sináptica. $\mathrm{O}$ aspecto essencial dessas sinapses é a presença de vesículas que são preenchidas por neurotransmissores que agem como mensageiros entre os neurônios $^{9,10}$ (Figura 1). Estas sinapses são geralmente unidirecionais e, por haver um breve intervalo de comunicação entre os terminais pré e pós-sinápticos, as sinapses químicas são mais lentas que as elétricas. Na microscopia eletrônica (ME) podemos classificar as sinapses químicas em: assimétricas excitatórias - que se caracterizam por apresentarem vesículas arredondadas e o terminal pós-sináptico proeminente denso; e sinapses simétricas inibitórias - que contêm vesículas pleomórficas ou alongadas sem densidade diferencial na fenda sináptica. ${ }^{11,12,13}$ Esta revisão está voltada ao estudo das sinapses químicas, as quais compreendem as sinapses verdadeiramente plásticas, por tanto as mais importantes para o funcionamento do sistema nervoso.
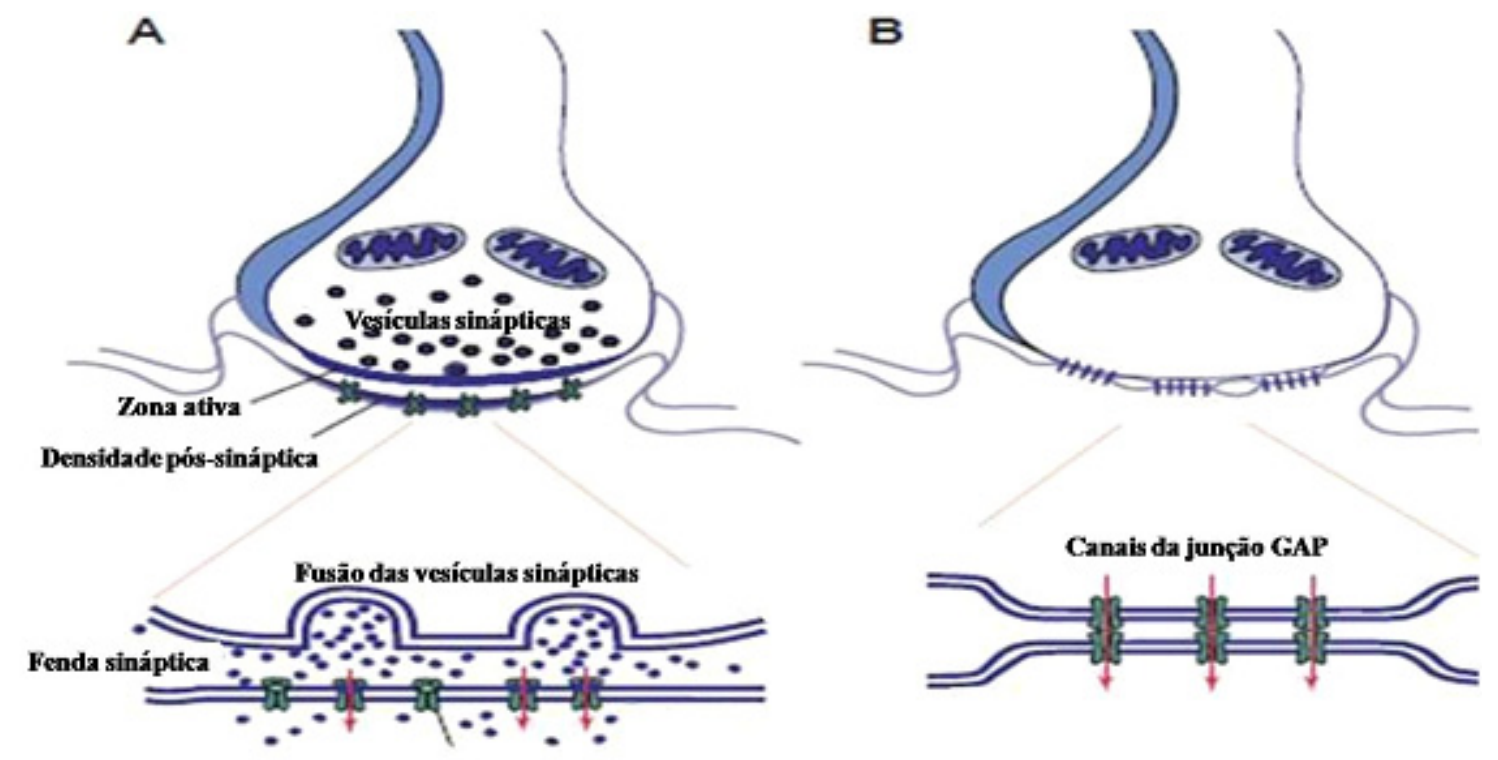

Figura 1: (A) Sinapse química: na zona ativa do terminal pré-sináptico encontramos um grande número de vesículas sinápticas que contém neurotransmissor, os quais após difusão pela fenda sináptica se ligarão a receptores específicos no terminal pós-sináptico. (B) Sinapse elétrica: presença de canais iônicos que formam poros para passagem de íons (Modificada de Cohen-Cory et al., 2002). 


\section{Os neurotransmissores}

A neurotransmissão é definida como a transmissão de informação entre neurônios ou entre neurônios e células glandulares ou musculares, a qual envolve o efeito de determinadas substâncias químicas que podem ser liberadas das vesículas sinápticas do terminal pré-sináptico de um neurônio, após estimulação elétrica. Após a liberação, os neurotransmissores agem em receptores específicos localizados em neurônios pós-sinápticos. Vistas na ME as vesículas sinápticas podem ser elétron-lúcidas (permitem a passagem de elétrons) ou elétron-densas (não permitem a passagem de elétrons). As vesículas elétron-lúcidas são pequenas (45-60 nm em diâmetro médio) e contém aminoácidos (glutamato, aspartato, GABA e glicina), os neurotransmissores dessas vesículas podem ter função excitatória ou inibitória. As vesículas elétron-densas são subdivididas em pequenas $(45-60 \mathrm{~nm}$ em diâmetro médio), as quais contêm aminas (dopamina, noradrenalina, adrenalina, serotonina e histamina), e grandes (cerca de $200 \mathrm{~nm}$ em diâmetro médio), as quais contêm neuropeptídeos (substância P, encefalina e angiotensina, por exemplo). ${ }^{14,15}$

A acetilcolina atua na junção neuromuscular como neurotransmissor excitatório. Foi o primeiro neurotransmissor identificado, em 1920, por Otto Loewi. No sistema nervoso central, diversos neurônios utilizam acetilcolina como neurotransmissor, sendo que as vias colinérgicas são amplamente distribuídas no prosencéfalo e tronco encefálico. A biossíntese da acetilcolina, catalisada pela enzima acetiltransferase de colina, envolve a transferência do grupamento acetila da acetil-CoA para a colina no terminal présinaptico. Essa reação é a etapa limitante deste processo biossintético. Na fenda sináptica pode ser degradada pela acetilcolinesterase, se dissociando em colina e acetato. Transportadores específicos dependentes de $\mathrm{Na}+$ carregam a colina de volta para o terminal pré-sináptico onde pode ser reutilizada para formação de neurotransmissor. Estas funções fazem do terminal pré-sináptico uma estrutura neuronal funcionalmente autônoma. Existem dois tipos de receptores para a acetilcolina, os receptores nicotínicos e os receptores muscarínicos, sendo os primeiros ionotrópicos (associados à abertura de canais iônicos) e os segundos metabotrópicos (acoplados a proteína G). 16,17

O aminoácido glutamato é o principal neurotransmissor excitatório no SNC. Neurônios glutamatérgicos são proeminentes no córtex cerebral e se projetam para estruturas subcorticais como hipocampo, complexo basolateral da amígdala, substância negra, estriado, núcleo subtalâmico, accumbens, colículo superior, núcleo caudado e rubro. A enzima glutaminase catalisa a conversão do precursor glutamina em glutamato. Não foi identificada nenhuma enzima envolvida com a degradação deste neurotransmissor na fenda sináptica. Diferente da degradação da acetilcolina (extracelular), o glutamato é carreado por transportadores específicos para o citoplasma de neurônios ou de células gliais, onde a enzima glutamina sintetase transforma o glutamato em glutamina, a qual pode ser transportada para dentro dos neurônios e formar mais neurotransmissor. O glutamato pode atuar tanto em receptores ionotrópicos (NMDA, AMPA e Cainato) como metabotrópicos (mGLU). ${ }^{16,17}$

$\mathrm{O}$ ácido gama aminobutírico (GABA) é o principal neurotransmissor inibitório do SNC. A enzima descarboxilase do ácido glutâmico (GAD) catalisa a conversão do precursor glutamato em GABA, sendo essa etapa dependente de vitamina B6, cofator da enzima. Os receptores GABAérgicos ionotrópicos (GABA A e C) são permeáveis ao íon Cl-, já os receptores GABA B são metabotrópicos. ${ }^{16,17}$

O aminoácido glicina é o principal neurotransmissor inibitório na medula espinhal. A síntese desse neurotransmissor ocorre a partir da serina por uma reação reversível dependente de folato e catalisada pelas enzimas glicina descarboxilase e serina hidroximetiltransferase. Após a ligação do neurotransmissor ao receptor ionotrópico da membrana pós-sináptica ocorre a abertura de canais permeáveis a íons $\mathrm{Cl}-$, promovendo a hiperpolarização da membrana neuronal. Após ser liberada na fenda sináptica, a glicina pode ser rapidamente removida por transportadores específicos de alta afinidade, chamados GLYT, localizados na membrana de neurônios e de células gliais. No tronco cerebral e na medula a neurotransmissão glicinérgica está envolvida no controle motor voluntário, na entrada do processamento sensorial e na geração de respostas reflexas. No tronco cerebral está relacionada a funções auditivas, cardiovasculares e respiratórias. Glicina e GABA podem estar co-localizados em interneurônios do corno dorsal da medula espinhal. ${ }^{16,17,18}$

Os neurotransmissores catecolaminérgicos (dopamina, noradrenalina e adrenalina) são sintetizados a partir da tirosina. A enzima tirosina hidroxilase transforma a tirosina em L-DOPA e a enzima DOPA descarboxilase transforma a L-DOPA em dopamina. Nos neurônios dopaminérgicos, a dopamina é armazenada nas vesículas sinápticas por transportadores específicos. No entanto, neurônios noradrenérgicos expressam a enzima dopamina-beta-hidroxilase no interior 
das vesículas sinápticas, sendo esta responsável por catalisar a conversão de dopamina em noradrenalina. Já os neurônios adrenérgicos, expressam a enzima fentolamina $\mathrm{N}$-metiltransferase, capaz de catalisar a conversão de noradrenalina em adrenalina no citoplasma do neurônio pré-sináptico. Todos os receptores catecolaminérgicos são metabotrópicos. A dopamina está envolvida principalmente com controle motor, sensações de satisfação e prazer, cognição e aprendizagem; e a noradrenalina com o controle do estado de vigília e alerta, regulação da pressão arterial e controle do humor. ${ }^{16,17,19}$

As vias serotoninérgicas possuem origem principal nos Núcleos da Rafe. A enzima triptofano hidroxilase catalisa a conversão de triptofano em 5-hidroxitriptofano e a enzima L-AADC converte essa substância em serotonina (5-hidroxitriptamina). Os receptores serotoninérgicos são classificados de 5HT-1 a 5HT-7. Sendo que o único receptor ionotrópico conhecido é o 5-HT3. A serotonina está envolvida com processos que regulam humor, sono, atividade sexual, apetite, funções neuroendócrinas, temperatura corporal, sensibilidade à dor, atividade motora e funções cognitivas. Atualmente vem sendo intimamente relacionada aos transtornos do humor ou transtornos afetivos e a maioria dos medicamentos chamados antidepressivos age produzindo um aumento da disponibilidade dessa substância na fenda sináptica. ${ }^{16,17,19}$

Além dos neurotransmissores clássicos têm-se estudado novos neurotransmissores como o ATP, o óxido nítrico e os endocanabinóides. ${ }^{20,21,22}$ Os endocanabinóides atuam como ligantes endógenos do receptor canabinóide CB1 que é o receptor metabotrópico mais abundante no encéfalo de mamíferos. Ao serem ativados, os receptores $\mathrm{CB} 1$ bloqueiam o influxo de $\mathrm{Ca}^{++}$e causam o bloqueio de canais dependentes de voltagem do tipo L. Como o influxo de cálcio é uma etapa importante para a liberação de vesículas de todos os neurotransmissores, o sistema canabinóide endógeno pode atuar como mensageiro inibitório de diversas sinapses do SNC. ${ }^{23,24,25}$ Por fim, é importante comentar que alterações na liberação de neurotransmissores estão envolvidas com a etiologia de diversas doenças, por exemplo, Parkinson (dopamina), epilepsia (GABA) e depressão (serotonina). ${ }^{26,27,28}$

\section{Mecanismos moleculares da Ilbera- ç̃o dos neurotransmissores}

A transmissão sináptica química se inicia quando um PA invade o terminal pré-sináptico levando à abertura dos canais de cálcio dependentes de voltagem. ${ }^{29,30,31}$ Sabe-se que a concentração de íons $\mathrm{Ca}^{++}$ no meio extracelular é muito mais elevada do que a do meio intracelular. Devido a este grande gradiente de concentração, a entrada de $\mathrm{Ca}^{++}$no neurônio é extremamente rápida e é essa transiente alta concentração de $\mathrm{Ca}^{++}$intracelular que permite a fusão das vesículas sinápticas com a membrana ${ }^{32}$ e a liberação dos neurotransmissores na fenda sináptica, os quais irão se ligar aos receptores pós-sinápticos. Após esta etapa, as vesículas sinápticas são recicladas via endocitose e reutilizadas para a liberação de mais neurotransmissores..$^{33,34,35}$

A maior parte dos neurônios possui mais de 500 terminais axonais pré-sinápticos e os PA que se iniciam no corpo celular viajam por todas as terminações nervosas indistintamente. Porém, nem todas as terminações nervosas convertem esses sinais em sinapses efetivas. ${ }^{36}$ Em muitos terminais apenas 10 a $20 \%$ dos PA se transformam em informação química. Essa relação entre PA e liberação sináptica nos terminais nervosos é regulada por mensageiros intracelulares, moduladores extracelulares e é dramaticamente alterada pelo uso repetitivo da sinapse, o que caracteriza a fadiga sináptica. Assim, além de maquinas secretoras, os terminais nervosos devem ser considerados unidades computacionais onde a relação entrada (PA) e saída (liberação dos neurotransmissores) é continuamente modificada em resposta aos sinais intracelulares e extracelulares. ${ }^{37}$

A Figura 2 sumariza o ciclo da vesícula sináptica. Primeiramente os neurotransmissores são ativamente transportados para dentro das vesículas via uma bomba de prótons que acidifica o lume das mesmas, gerando um gradiente de $\mathrm{pH} .{ }^{38,39}$ As vesículas se organizam em grupo, originando o chamado cluster de vesículas sinápticas, e se posicionam próximo à zona ativa pré-sináptica. As vesículas se ancoram à membrana e a ela se ligam, fase essa chamada de priming ou iniciação. É nessa fase que as vesículas são consideradas competentes, já que com uma nova entrada de $\mathrm{Ca}^{++}$elas poderão se fundir à membrana e liberar os neurotransmissores. ${ }^{40,41}$ A reciclagem das vesículas acontece por meio de pelo menos três prováveis processos endocíticos: reutilização local; reciclagem rápida sem envolvimento endossomal; ou endocitose mediada por clatrina que pode ser com ou sem intermédio endossomal. ${ }^{42,43,44}$

As vesículas sinápticas possuem um diâmetro de 20 a $40 \mathrm{~nm}$, são abundantes e sua única função conhecida é a de armazenar e liberar neurotransmis- 


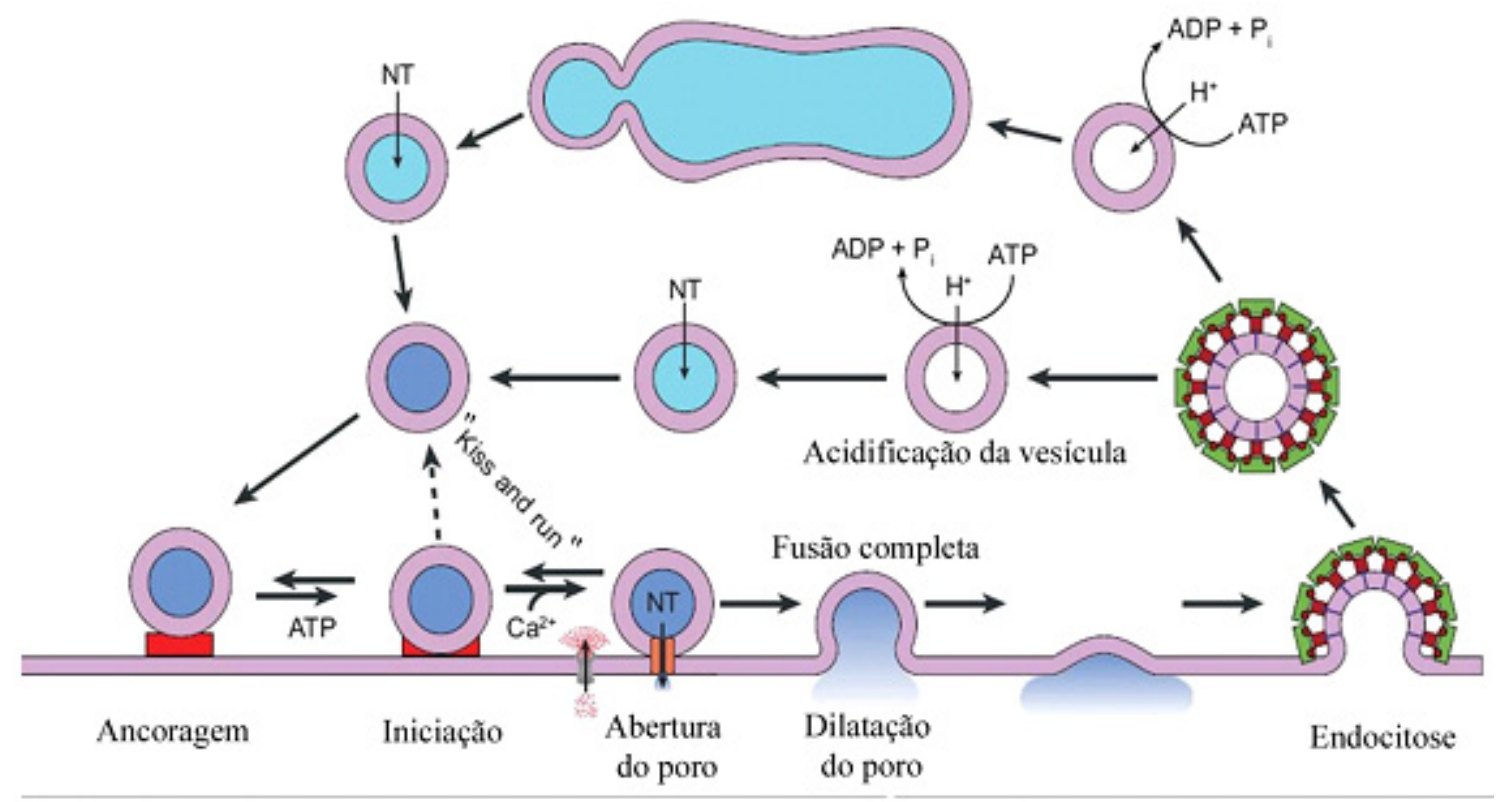

Figura 2: O ciclo da vesícula sináptica. Primeiramente os neurotransmissores são ativamente transportados para dentro das vesículas sinápticas graças a uma bomba de prótons que acidifica o lume das mesmas, gerando assim um gradiente de $\mathrm{pH}$. Quando recarregadas, as vesículas se organizam em cluster e se posicionam próximas à zona ativa pré-sináptica. Após essa etapa, as vesículas se ancoram e se ligam à membrana pré-sináptica, fase essa chamada de priming ou iniciação, o que as torna competentes para sua fusão e abertura. Com a entrada de $\mathrm{Ca}++$ elas se fundem, liberam o neurotransmissor e são recicladas por meio de pelo menos três prováveis vias endocíticas: reutilização local; reciclagem rápida sem envolvimento endossomal; ou endocitose mediada por clatrina com ou sem intermédio endossomal (Modificada de Chapman, 2008).

sores. Elas são relativamente simples, com uma razão proteína: fosfolípides de 1:3. Seus fosfolipídios são compostos em $40 \%$ por fosfatidilcolina, $32 \%$ por fosfatidiletanolamina, $12 \%$ por fosfatidilserina, $5 \%$ por fosfatidilinositol e $10 \%$ por colesterol. ${ }^{45} \mathrm{O}$ número de proteínas constitutivas, aparentemente presentes em todos os tipos de vesículas, é menor de 50. Essas proteínas são divididas em dois grupos: proteínas de transporte envolvidas com a captação de neurotransmissores, e as proteínas de tráfego que participam dos processos de exocitose, endocitose e reciclagem vesicular. Proteínas de transporte são compostas pelas bombas de prótons que geram o gradiente eletroquímico necessário para a captação dos neurotransmissores. As proteínas de tráfego são mais complexas e incluem proteínas intrínsecas de membrana. ${ }^{37}$

A captação dos neurotransmissores para dentro das vesículas é mediada por sete diferentes transportadores. O glutamato é captado por três deles ${ }^{46,47}$, as monoaminas por outros dois ${ }^{48,49}$ e um único transportador foi identificado para GABA e glicina ${ }^{50,51} \mathrm{e}$ um outro para acetilcolina. ${ }^{52}$ Pouco se sabe sobre a regulação da captação dos neurotransmissores e como isso realmente ocorre. Acredita-se que esta seria regulada tanto pela bomba quanto pelos transportadores e seria dependente da concentração de moléculas dos neurotransmissores. ${ }^{53,54}$

A fusão da membrana vesicular com a membrana pré-sináptica geralmente envolve proteínas do grupo SNARE (Figura 3), presentes tanto na membrana pré-sináptica (sintaxina 1 e SNAP-25) quanto nas vesiculares (sinaptobrevina). ${ }^{55-58} \mathrm{O}$ complexo protéico que aproxima as duas membranas é formado pelo motivo R-SNARE da sinaptobrevina, pelo motivo Qa-SNARE da sintaxina 1, e pelos motivos Qb- e Qc-SNARE da SNAP-25. O complexo SNARE apenas aproxima as vesículas da membrana criando um intermediário instável incapaz de abrir o poro de fusão. ${ }^{59}$ A maquinaria de fusão das membranas vesicular e pré-sináptica se inicia com a proteína sinaptotagmina, presente na membrana da vesícula sináptica. A sinaptotagmina 1 é fundamental para a ancoragem, fusão e reciclagem da vesícula sináptica ${ }^{60} \mathrm{~A}$ fusão e a ancoragem são mecanismos dependentes de $\mathrm{Ca}^{++},{ }_{1}$ sendo o domínio $\mathrm{C} 2 \mathrm{~A}$ diretamente relacionado à fusão das vesículas. ${ }^{62} \mathrm{O}$ domínio $\mathrm{C} 2 \mathrm{~A}$ da sinaptotagmina é capaz de se ligar a 3 íons $\mathrm{Ca}^{++}$e o $\mathrm{C} 2 \mathrm{~B}$ a 2 íons. A sinaptotagmina pode se ligar ao complexo SNARE na ausência de $\mathrm{Ca}^{++}$, mas precisa do $\mathrm{Ca}^{++}$para fundir-se com a membrana fosfolipídica. ${ }^{63}$ Acredita-se 
que a ligação do domínio C2A da sinaptotagmina ligada à membrana pré-sináptica resulte na inserção parcial de aminoácidos hidrofóbicos na mesma e o estresse mecânico aí induzido desestabilizaria a membrana e causaria a abertura do poro. ${ }^{63}$ (Figura 3).

A formação do complexo SNARE na sinapse e outras funções intracelulares são provavelmente controladas por uma classe de proteínas chamadas SM. Dentre elas existe a proteína Munc18-1 que se liga a sintaxina na conformação fechada da mesma e bloqueia seu motivo de participação no complexo SNARE. ${ }^{64}$ Já o complexo formado pelas proteínas Rab3, RIM1 e Munc13-1 podem catalisar a conversão da sintaxina 1 para a conformação aberta. ${ }^{65}$ (Figura 3). Outro mecanismo de controle é efetivado pelas sinaptofisinas presentes nas vesículas que se li- gam à sinaptobrevina e impedem sua ligação ao complexo SNARE. 66,67

Acredita-se que possa haver pelo menos 3 vias de reciclagem da vesícula sináptica: 1- A via do "kissand-stay", quando as vesículas são reacidificadas e preenchidas com neurotransmissor sem se desgrudarem da membrana pré-sináptica, permanecendo assim diretamente no pool de vesículas já preparado para liberação. 2- A via do "kiss-and-run", onde as vesículas são desancoradas e recicladas localmente, reacidificadas e completadas com neurotransmissores nos primeiros passos do ciclo. 3- A endocitose mediada pela proteína clatrina, em que o ciclo retorna ao ponto inicial, a vesícula é reacidificada e preenchida com neurotransmissores de maneira direta ou por intermédio endossomal ${ }^{37}$ (Figura 3).
(A) Proteinas do Complexo SNARE

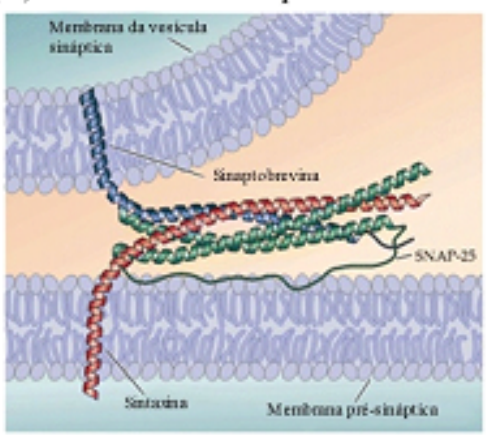

(B) Exocitose das vesículas
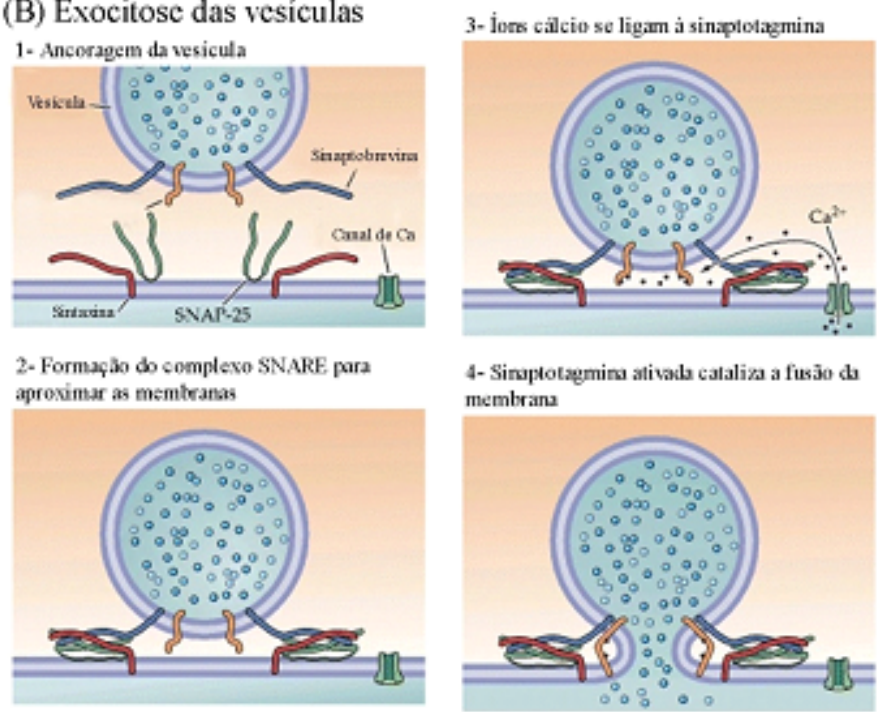

4- Sinsptotagmina ativada calaliza a fusão da membrans

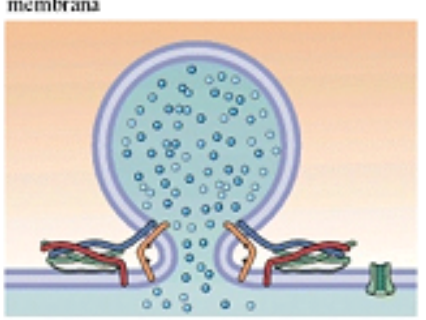

(C) Regulação da formação do complexo SNARE

(1)

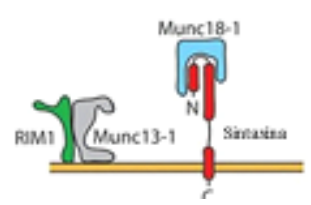

(2)

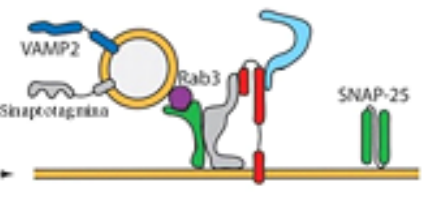

(3)

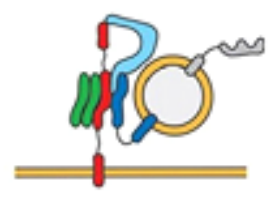

Figura 3: Proteínas envolvidas na exocitose das vesículas sinápticas. Em A, as proteínas SNARE: sinaptobrevina em azul forma um complexo em hélice com as proteínas sintaxina em vermelho e SNAP-25 em verde. Em B, etapas da exocitose das vesículas sinápticas. O complexo SNARE reúne as duas membranas e os íons Ca++ se ligam à sinaptotagmina, o que faz com que a região citoplasmática dessa proteína se insira na membrana plasmática pré-sináptica e catalise a fusão das membranas. Em C, principais proteínas envolvidas na regulação do complexo SNARE. (1) A proteína Munc18-1 se liga à conformação fechada da proteína sintaxina e bloqueia seu motivo de participação no complexo SNARE. (2) Complexo formado pelas proteínas Rab3, RIM1 e Munc13-1 pode catalisar a conversão da sintaxina para sua conformação aberta. (3) SNAP-25 se liga a sintaxina para iniciar a formação do complexo SNARE que é ligado a VAMP2 nas vesículas resultando na conformação final do complexo SNARE (Modificada de Purves et al., 2005). 
A endocitose mediada por clatrina se inicia quando as proteínas AP180 e AP-2 se juntam às moléculas de clatrina iniciando a invaginação da membrana vesicular. ${ }^{68,69}$ Depois da formação de um "broto de clatrinas", as proteínas dinamina e ampifisina formam um laço ao redor do pescoço da região invaginada. ${ }^{68,70}$ Finalmente, o desprendimento da clatrina acontece quando Hsc70 é recrutada com o auxilio das proteínas auxilina e sinaptojanina. ${ }^{68,71,72}$ Segundo a literatu$\mathrm{ra}$, as funções do complexo dinanina/sinaptofisina na endocitose das vesículas sinápticas parecem ser independentes de clatrina. ${ }^{73}$ Apesar do conhecimento sobre as vias endocíticas, a maior parte dos cientistas acredita que a via mediada por clatrina seja a via mais comum, embora a maior parte dos estudos demonstra que há um longo tempo para a reciclagem por esta via, comparado ao tempo de 1 milisegundo da liberação sináptica. Porém se a atividade de qualquer uma das proteínas envolvidas no processo da clatrina for perturbada ocorre a inibição da transmissão sináptica. ${ }^{37,68}$ De qualquer maneira, os mecanismos por trás da via do "kiss and run" ainda são pobremente entendidos. ${ }^{68,74,75}$

\section{Composição molecular e funcional dos espinhos dendríticos e da den- sidade pós-sináptica}

Uma sinapse é tipicamente definida pela presença de uma zona pré-sináptica ativa contendo as vesículas sinápticas, uma fenda sináptica bem definida e uma densidade pós-sináptica (PSD) ${ }^{76}$ As sinapses podem ser axo-espínicas, axo-axônicas, axo-somáticas, somato-dendríticas, dendro-axônicas e dendro-dendríticas.

Os espinhos dendríticos são minúsculas protrusões que surgem a partir dos ramos dendríticos e, desde a primeira descrição em 1888 por Ramon y $\mathrm{Cajal}^{77}$, têm sido alvo de estudo. Reconstruções a partir da ME mostraram que os espinhos dendríticos são estruturalmente diversos. Suas formas incluem protrusões finas semelhantes à filopódios (espinhos do tipo thin), espinhos curtos e sem um pescoço bem definido (espinhos do tipo stubby) e espinhos com uma larga cabeça em forma de bulbo (espinhos do tipo mushroom) ${ }^{78}$ (Figura 4).

Os espinhos dendríticos podem ser encontrados em neurônios de diversas estruturas encefálicas e em uma variedade enorme de espécies. São estruturas que apresentam plasticidade, ou seja, são altamente dinâmicas, particularmente durante o desenvolvimento pós-natal, quando um enorme número de conexões sinápticas são feitas. ${ }^{79,80}$ Durante a fase adulta, os espinhos dendríticos participam de processos de aprendizagem e memória e estão relacionados a algumas patologias, incluindo retardo mental e distúrbios neurodegenerativos. ${ }^{81,82,83}$ Todos esses processos são dinâmicos e envolvem mudanças substanciais na quantidade e na morfologia dos espinhos. ${ }^{84}$

Os espinhos dendríticos apresentam como principais componentes intracelulares polirribissomos, endossomos, retículo endoplasmático liso (podendo formar o aparato do espinho, uma especialização do retículo endoplasmático liso com importante papel no controle da homeostase do $\mathrm{Ca}_{2}^{+}$), actina e a PSD (Figura 4)..$^{85,86}$

A PSD é visualizada na ME como uma zona elétron-densa. Sua superfície varia desde pequenos discos até largas formas irregulares que podem ser intercaladas por regiões elétron-lúcidas. De acordo com a PSD, uma sinapse pode ser definida como macular, na qual a PSD cobre uma pequena área contínua e são mais ou menos convexas; ou perfurada, em que a PSD exibe perfurações. A PSD é composta por centenas de proteínas incluindo receptores do tipo NMDA, AMPA, receptores metabotrópicos de glutamato, proteínas scaffold, proteínas de sinalização celular, enzimas, componentes do citoesqueleto e canais iônicos. As centenas de componentes da PSD se associam por uma série de interações protéicas, o que caracteriza a PSD como uma das mais complexas organelas sináptica. ${ }^{87}$

As interações protéicas na PSD ocorrem por proteínas que apresentam domínios PDZ. O nome PDZ é derivado das primeiras proteínas em que esse domínio foi descoberto (PSD-95, Dlg, ZO-1). Os domínios PDZ são cadeias de aproximadamente 100 aminoácidos especializados em se ligar a pequenos peptídeos na extremidade carboxi-terminal de outras proteínas. Por se ligar a peptídeos particulares, cada proteína PDZ pode formar grandes complexos moleculares em regiões subcelulares específicas. Essas proteínas podem ainda se movimentar dentro dos neurônios e sua atividade e expressão é altamente regulada. ${ }^{88}$

Foi demonstrado através de estudos genéticos, morfológicos e eletrofisiológicos que as interações protéicas que ocorrem na PSD são essenciais para controlar a estrutura, a força e a plasticidade das sinapses. Por exemplo, as interações que ocorrem em resposta a processos de plasticidade sináptica de longa dura- 

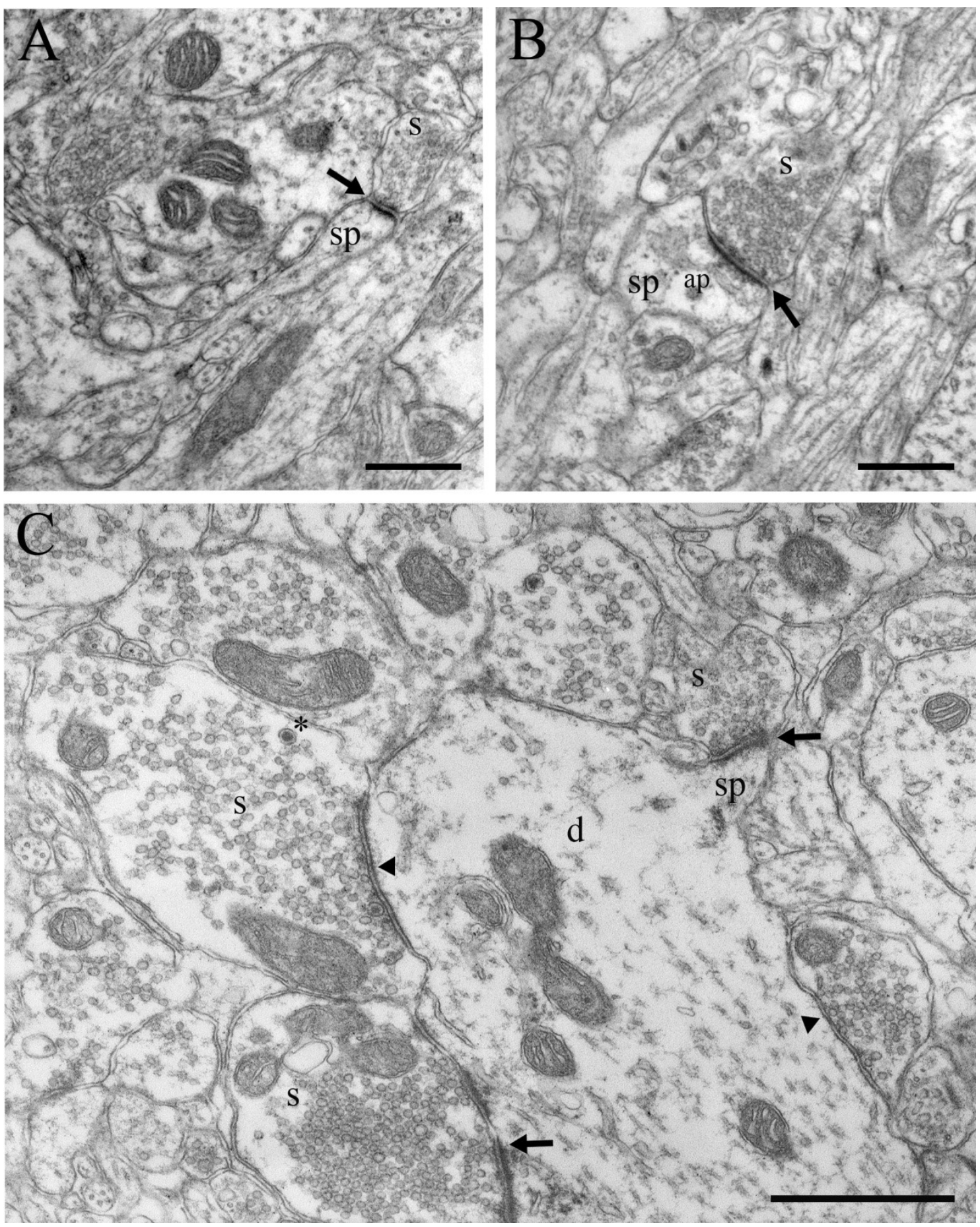

Figura 4: Microscopia Eletrônica do SNC (A) Sinapse excitatória (seta) em um espinho do tipo thin. (B) Sinapse excitatória (seta) em um espinho do tipo cogumelo com o aparato do espinho (ap). Perceber a presença de vesículas redondas e a assimetria da PSD em A e B. (C) diferentes sinapses em um ramo dendrítico (d), duas inibitórias pela presença de vesículas achatadas e simetria da elétrondensidade entre os terminais pré e pós-sinápticos (cabeça de seta) e duas sinapses excitatórias, uma no dendrito e outra em um espinho do tipo stubby (seta). Perceber a vesícula sináptica grande de centro elétron-denso marcada pelo asterisco. $\mathrm{s}$, terminal présináptico; sp, espinhos. Barra = $1 \mathrm{~m}$ (Modificado de Rasia-Filho et al., 2009). 
ção tais como potenciação (LTP) ou depressão de longa duração (LTD) podem resultar, respectivamente, em reforço ou enfraquecimento de uma sinapse, acompanhado de aumento ou diminuição do volume de um espinho dendrítico (Figura 5). Esse rearranjo estrutural permite maior variabilidade e consequentemente maior número de circuitos gerados no cérebro, resultando em maior capacidade de memória por sinapse. ${ }^{76}$ Além disso, a plasticidade estrutural pode estar envolvida na recuperação de traumas cerebrais..$^{89,90,91}$ O aumento do conhecimento da estrutura e função da PSD pode fazer com que as interações protéicas via domínios PDZ sejam alvo de intervenções farmacológicas, abrindo assim uma variedade imensa de possibilidades para o tratamento de neuropatologias.

A relação da importância de moléculas controlando a morfologia dos espinhos dendríticos e a cognição foi elucidada em um trabalho de Ramakers ${ }^{92}$, que mostra que genes que codificam proteínas que regulam a dinâmica dos espinhos dendríticos estão mutados no retardo mental não-sindrômico ligado ao cromossomo X, uma patologia que se acredita estar limitada a mecanismos especificamente envolvidos com aspectos cognitivos. ${ }^{92}$

Uma superfamília de proteínas de membrana da PSD associadas à guanilato quinase, as proteínas MAGUK, estão presentes em sinapses glutamatérgicas excitatórias e são responsáveis por organizar receptores ionotrópicos de glutamato e suas proteínas de sinalização celular, regulando assim a força das sinapses. ${ }^{93}$ Modificações na função das proteínas MAGUK em sinapses glutamatérgicas como, por exemplo, modificações na interação dessas proteínas com receptores NMDA, são eventos comuns em vá- rios distúrbios neurodegenerativos e em processos de excitotoxidade. ${ }^{94,95,96}$ As proteínas MAGUK são alvos moleculares da manipulação genética e farmacológica e poderão originar novas terapias para distúrbios cerebrais, tais como a doença de Parkinson, Alzheimer, Huntington e Esquizofrenia. ${ }^{97}$

\section{Transdução de sinal}

As informações passadas de um neurônio a outro precisam ser transduzidas quando as moléculas por si só não conseguem gerar uma resposta. A ligação de uma substância (neurotransmissor) aos receptores pode fazer com que ocorra a transdução do sinal para a célula. Os receptores sinápticos são classificados em dois grupos, ionotrópicos e metabotrópicos ligados à proteína $\mathrm{G}$, dependentemente da resposta que vão gerar.

Os receptores ionotrópicos estão associados a canais iônicos ativados por uma molécula, que no caso do sistema nervoso, seria o neurotransmissor. Quando uma molécula do neurotransmissor se liga a um receptor ionotrópico o canal iônico associado se abrirá ou se fechará, induzindo potenciais pós-sinápticos excitatórios (PEPS) ou inibitórios (PIPS) de acordo com o canal iônico que o neurotransmissor abrir. Por exemplo, a passagem de $\mathrm{Na}^{+}$eleva o potencial de membrana até ser atingido o limiar de ação e ser desencadeado o PA e consequente excitação neuronal. A maioria dos canais aniônicos permite a passagem de $\mathrm{Cl}^{-}$, o que aumenta o número de cargas negativas intracelulares, aumentando a distância do potencial de membrana do limiar de ação e gerando um potencial inibitório. A seletividade iônica dos canais a cátions se

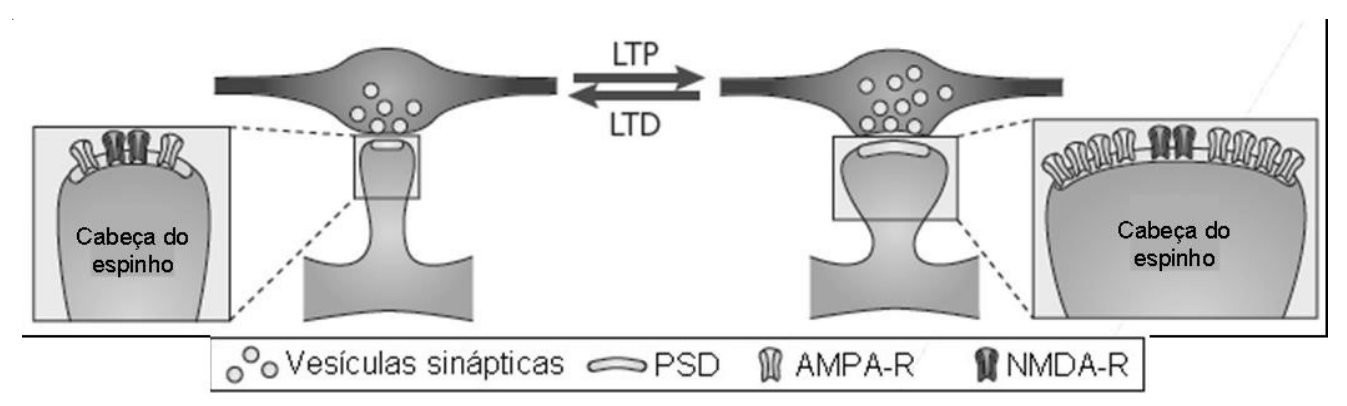

Figura 5: Mudanças no volume do espinho podem ser interpretadas como mudanças na força da sinapse. O volume do espinho é proporcional à área da PSD, que por sua vez é proporcional à quantidade de receptores AMPA e NMDA na membrana da cabeça do espinho. Essa quantidade de receptores também varia de acordo com os parâmetros pré-sinápticos que controlam a eficiência da liberação de glutamato tais como o tamanho da zona ativa e a disponibilidade de vesículas. O volume do espinho e a sensibilidade póssináptica aumentam após LTP. O contrário ocorre após LTD (Modificado de Holtmaat e Svoboda, 2009). 
dá graças ao revestimento desses canais por cargas negativas que atraem cátions e repelem ânions. A seletividade dos canais aniônicos se dá pelo diâmetro do poro do canal, já que os cátions são moléculas maiores. ${ }^{98}$ Sendo assim, na maioria dos casos, tem-se um PEPS quanto os íons com carga positiva se movimentam através da membrana de modo a tornar o neurônio mais positivo interiormente, e PIPS quando o movimento de íons torna a célula mais negativa interiormente.

O receptor metabotrópico foi nomeado pela primeira vez em 1982 por Conn e colaboradores ${ }^{99}$ durante estudo do hormônio liberador de gonadotrofina e, em 1993, Maggio e colaboradores ${ }^{100}$ esclareceram sua existência em receptores muscarínicos. Mas apenas em 1994, Alfred G. Gilman e Martin Rodbell ${ }^{101,102}$ ganharam o Prêmio Nobel de Fisiologia e Medicina pelo descobrimento dos receptores acoplados a proteínas $\mathrm{G}$.

A Proteína $\mathrm{G}$ é uma proteína complexa formada por três subunidades $(\alpha, \beta$ e $\gamma)$ que funciona como um transdutor de sinais. ${ }^{103}$ Quando o receptor não está na presença do ligante, a subunidade está ligada a uma molécula de GDP e quando o neurotransmissor se liga ao receptor o GDP é trocado pelo GTP e a proteína G se torna ativa e age sobre uma molécula efetora. ${ }^{103}$ Quanto a conformação molecular, os receptores são formados por sete segmentos transmembrana hélice, um domínio extracelular para interação com o neurotransmissor (amino terminal), e um domínio intracelular para interação com proteínas $\mathrm{G}$ (carboxi terminal), onde pode ocorrer desensibilização por fosforilação, por bARK ou por proteína quinase A. ${ }^{16,103,104}$ Conforme a célula-alvo é possível encontrar diferentes subtipos de proteínas $\mathrm{G}\left(\mathrm{G}_{\mathrm{s}}, \mathrm{G}_{\mathrm{i}}\right.$ e $\left.\mathrm{G}_{\mathrm{o}}\right){ }^{105}$

Contudo, esses receptores são denominados metabotrópicos porque, além de produzirem a abertura de canais iônicos, agem através de segundos mensageiros que também possuem a capacidade de produzir uma série de alterações neuronais, como alterações metabólicas de longo prazo que podem alterar a expressão gênica de determinadas proteínas. ${ }^{104}$

Os receptores inotrópicos têm a vantagem de causar uma resposta direta e muito mais rápida que os metabotrópicos, pois não precisam de uma cascata de sinalização para gerar uma resposta. Do mesmo jeito eles também têm desvantagens em relação com os receptores metabotrópicos, já que a relação neurotransmissor/canal é de 1:1, enquanto nos receptores metabotrópicos pode ser de 1: a muitos. ${ }^{103}$
Apesar de ainda faltar muito a descobrir sobre o mecanismo de ação das proteínas $\mathrm{G}$, atualmente já se tem esclarecido alguns dos processos e moléculas envolvidas nas cascatas de sinalização, as quais serão descritas a seguir.

\section{Proteína G e o sistema da adenilciclase (AC)}

A AC é uma das enzimas chave que uma vez ativada pela proteína $\mathrm{G}$ produz um segundo mensageiro conhecido como cAMP. ${ }^{103} \mathrm{O}$ neurotransmissor noradrenalina, por exemplo, quando se liga ao receptor do tipo ativa o sítio Gs da proteína G. A subunidade ativa a AC que, a partir do ATP, produzirá o segundo mensageiro, o cAMP. O cAMP tem a função de ativar uma enzima quinase A (PKA) cuja função é fosforilar canais de $\mathrm{Ca}^{++} .98$

Outro tipo de receptor de noradrenalina é um tipo 2 que tem efeito antagônico, ou seja, inibe a AC. A inibição da enzima levará a ausência da produção de cAMP e, como consequência, os canais de $\mathrm{K}^{+}$que estavam abertos, se fecharão. Sendo assim, um mesmo neurotransmissor pode ter receptores que agem diferentemente e assim apresentar efeitos antagôni$\cos .{ }^{106}$

\section{Proteína G e o sistema da fosfolipase C (PLC)}

Outros receptores metabotrópicos ativam outra enzima chave: a PLC, que como a AC está inserida na membrana plasmática. A PLC age na membrana fosfolipídica quebrando o inositol fosfolipídio em dois componentes: IP3 (hidrossolúvel) e DAG (lipossolúvel). O DAG ativa a proteína quinase $\mathrm{C}$ (PKC) enquanto o IP3 difunde-se para o citosol e leva a abertura de canais de $\mathrm{Ca}^{++}$dos reservatórios do retículo endoplasmático. A presença de $\mathrm{Ca}^{++}$intracelular altera o metabolismo do neurônio pós-sináptico assim como a condutância iônica, mudando a excitabilidade celular. Este é um dos mecanismos de ação da serotonina, por exemplo. ${ }^{106}$

As células possuem mecanismos capazes de reverter estes efeitos, graças a enzimas que desfosforilam as moléculas fosfatadas pelas quinases. Essas enzimas são as fosfatases. O efeito dos receptores metabotrópicos sobre os canais iônicos dependerá do balanço entre as reações de fosforilação e de desfosforilação. ${ }^{107}$

Como consequência, o estudo desses mecanismos vem sendo cada vez mais importante, pois estão envolvidos em muitos processos, e tem sido alvo do estudo de novos fármacos. Pesquisas recentes encon- 
traram que alterações nas proteínas G estão envolvidas em muitas doenças como o Parkinson, onde se encontram alterações na proteína $\mathrm{G}$ dos receptores de adenosina A2 e dopamina D2; o hipogonadismo hipogonadotrópico, com polimorfismos do receptor do hormônio liberador de gonadotrofina, vasopressina 2, dopamina D3 e receptor liberador do hormônio luteinizante; esquizofrenia e psicoses, com mutações na proteína $\mathrm{G}$ dos receptores metabotrópicos de glutamato 2 (mGLUR2) e de serotonina (5HT2a) ${ }^{105}$, além de muitas outras que são mostradas na Tabela 1 .

\section{Tabela 1}

Relação entre doenças e função da proteína $\mathrm{G}$ (Modificada de Nurnberg et al., 1999).

\begin{tabular}{lc} 
Doença & Função da proteína G \\
\hline $\begin{array}{l}\text { Cegueira de cores, degeneração } \\
\text { de retina, cegueira noturna }\end{array}$ & Diminuição \\
$\begin{array}{l}\text { Deficiência de glicocorticóide } \\
\text { congênita }\end{array}$ & Diminuição \\
Doença de Hirschsprung & Diminuição \\
Síndrome McCune-Albright & Aumento \\
Adenoma do córtex adrenal & Aumento \\
Tumor tiroidal da pituitária & Aumento \\
Tumores adrecorticais nos ovários & Aumento \\
\hline
\end{tabular}

\section{Alterações na transmissão sinápti- ca e doenças neurodegenerativas}

O estudo das doenças neurodegenerativas, como Parkinson e Alzheimer, tem avançado muito na última década. A doença de Alzheimer é a doença neurodegenerativa mais comum, sendo seguida pela doença de Parkinson.

A doença de Alzheimer é caracterizada por três grupos de sintomas: disfunção cognitiva, sintomas psiquiátricos e distúrbios do comportamento com o comprometimento na execução de atividades diárias rotineiras. ${ }^{108}$ A principal característica morfológica da doença de Alzheimer é o acúmulo de agregados peptídicos extracelulares, conhecidos como placas senis, encontrados no neocórtex cerebral e hipocampo. Outra característica da doença de Alzheimer é o acúmulo intracelular de uma proteína associada à microtú- bulos, a proteína TAU, que quando anormalmente fosforilada forma emaranhados neurofibrilares. ${ }^{109,110}$

A doença de Alzheimer é caracterizada por mudanças sinápticas induzidas pelos produtos de degradação da proteína precursora amilóide. A injeção intra-axonal do oligomérico $A \beta 42$, mas não do oligomérico $\mathrm{A} \beta 40$ (ambos intracelulares) ou $\mathrm{A} \beta 42$ (extracelular), inibe agudamente a transmissão sináptica na sinapse gigante da lula Loligo pealei. ${ }^{111}$ A lula, por seu axônio gigante, e outros invertebrados são muito utilizados como modelos experimentais nos estudos de transmissão sináptica devido à facilidade de manipulação durante os estudos.

A doença de Parkinson é caracterizada clinicamente por tremores, lentidão de movimentos, problemas de equilíbrio e rigidez dos membros. Estudos sugerem que a doença resulta da perda de neurônios da substância negra do mesencéfalo, responsável pela produção do neurotransmissor dopamina, mensageiro químico envolvido na coordenação de movimentos. No entanto, as causas da morte dos neurônios na doença de Parkinson não são totalmente conhecidas. ${ }^{112,113}$

Estudos mais atuais, aonde o axoplasma da lula Loligo pealeii foi injetado 1-methyl-4-phenylpyridium $\left(\mathrm{MPP}^{+}\right)$, utilizado como neurotoxina em modelos experimentais para essa doença, demonstraram que o $\mathrm{MPP}^{+}$causa aumento do transporte axonal rápido retrógrado dependente da dineína citoplasmática e reduz o transporte axonal rápido retrógrado dependente da cinesina. Os autores sugerem que essas alterações podem ser eventos primários na patogênese da doença de Parkinson. ${ }^{114}$ Além disso, a injeção de $\mathrm{MPP}^{+}$no terminal pré-sináptico do axônio gigante da lula Loligo peallei bloqueia a transmissão sináptica, sendo observado redução no número de vesículas contendo neurotransmissores na zona ativa pré-sináptica desses animais quando comparados a controles. ${ }^{115}$

A injeção pré-sináptica da cadeia leve da toxina botulínica C1 no axônio gigante da lula Loligo peallei leva ao bloqueio da transmissão sináptica. ${ }^{116}$

Esses estudos demonstram que as causas iniciais de doenças neurodegenerativas, como Alzheimer e Parkinson, e de muitas outras doenças que afetam o sistema nervoso podem estar relacionadas a alterações no transporte axonal e ao bloqueio da transmissão sináptica, com posteriores eventos subsequentes, como a morte neuronal. Estudos em nível molecular são fundamentais para o entendimento dessas doenças. 


\section{Conclusões}

Este texto procurou revisar os principais mecanismos moleculares envolvidos na transmissão sináptica, desde a biossíntese dos neurotransmissores e a degradação ou recaptação dos mesmos na fenda sináptica, até os mecanismos moleculares que levam a liberação dos neurotransmissores (a importância de haver uma concentração adequada de íons $\mathrm{Na}^{+}, \mathrm{K}^{++}$, $\mathrm{Cl}^{-}$e $\mathrm{Ca}^{++}$), a composição da densidade pós-sináptica e dos espinhos dendríticos, assim como os mecanismos de transdução do sinal que geram uma resposta na célula pós-sináptica. É importante mencionar que alterações em muitos desses processos estão relacionados a doenças neurodegenerativas e afetivas, ou seja, as pesquisas nessas áreas, tanto experimentais quanto clínicas, são fundamentais para a compreensão desses mecanismos em condições fisiológicas e patológicas.

\begin{abstract}
In the nervous system, the synapse is the structure that allows a neuron pass an electrical or chemical signal to another neuron or another cell (muscle or glandular). The word synapse comes from "synaptein" that Sir Charles Scott Sherrington and his colleagues minted from the Greek "syn" (together) and "haptein" (buckling). Most part of the synaptic transmission is performed through chemical synapses. Chemical synapses have a slower response than the electric ones; they have the advantage of amplifying the signal generated through a cascade of second messengers. Chemical synapses can be excitatory or inhibitory and are characterized by a presynaptic terminal (where there are vesicles that contain the neurotransmitters) in contact with a postsynaptic terminal (where there are the ionotropic and metabotropic receptors) separated by the synaptic cleft. Synapses can occur on axons (axo-axonal), on dendrites (axodendritic), on soma (axo-somatic) and on dendritic spines. Dendritic spines are small profusions with the function of synaptic compartmentalization. There is much information about classic neurotransmitters, such as acetylcholine, glutamate, GABA, glycine, dopamine, norepinephrine, and serotonin, but the study of new neurotransmitter (i. e., ATP, nitric oxide, endocannabinoids, and neuropeptides) has advanced enormously. This review is a collection summary of key information from the recent literature describing the molecular and functional aspects of the cycle of synaptic vesicle, the composition of postsynaptic density, dendritic spines, and signal transduction.
\end{abstract}

Key words: Synaptic Transmission. Synaptic Proteins. Receptors, Neurotransmitter.

\section{Referências bibliográficas}

1. Purkinje JE. Neueste untersuchungen aus der nerven- und hirn-anatomie. In: Llinás, R. The squid giant synapse: a model for chemical transmission. Oxford University Press; New York: 1999; $177-80$.

2. Deiters O. Untersuchungen über Gehirn und Rückenmark. Braumschweig, Vieweg, 1865.

3. Ramón y Cajal S. Revista trimestral de histologia normal y patológica, 1888; In: Ramón y Cajal S. Histology of the nervous system, tradução de Swanson N \& Swanson LW, Oxford University Press; New York :1995; xxiv-xxv.

4. Brick LG, Coombs JS, Eccles JC. The recording of potentials from motoneurones with an intracellular electrode. J Physiol. 1952; 117: 431-60.

5. Bennett MV, Zukin RS. Electrical coupling and neuronal synchronization in the Mammalian brain. Neuron. 2004; 41:: 495511.

6. Eccles JC. Developing Concepts of the Synapses. The Journal of Neuroscience 1990; 10: 3769-81. J. neurosci.

7. Hormudzi SG, Filippov MA, Mitropoulou G, Monyer H, Bruzzone R. Electrical synapses: a dynamic signaling system that shapes the activity of neuronal networks. Biochim. biophys. acta, Biomembr. 2004; 1662: (1-2): , 23: 113-137.

8. Fukuda T. Strucutural Organization of the Gap Junction in the Cerebral Cortex. Neuroscientist. 2007; 13: 199-207.

9. Burns ME, Augustine GJ. Synaptic Structure and Function: Dynamic Organization Yields Architectural Precision. Cell 1995; 83: 187-94.

10. Cohen-Cory S. The developing synapse: construction and modulation of synaptic structures and circuits. Science 2002; 298: 770-6. Science (Wash.).

11. Gray EG. Axo-somatic and axo-dendritic synapses of the cerebral cortex. An electron microscope study. J Anat. 1959; 93: 420-33.

12. Colonnier M, Synaptic patterns on different cell types in the different laminae of the cat visual cortex: an electron microscope study. Brain Res. 1968; 9; 268-87.

13. Peters A. Golgi, Cajal, and the fine structure of the nervous system. Brain Res Rev. 2007, 256-63.

14. Gibbins IL, Morris JL. Structure of peripheral synapses: autonomic ganglia. Cell Tissue Res. 2006; 326: 205-20.

15. Osborne RH. Insect Neurotransmission: Neurotransmitters and Their Receptors. Pharmacol Ther. 1996; 69: 117-42. 
16. Halbach von $\mathrm{O}$ und $\mathrm{H}$ and Dermietzel R. Neurotransmitters and Neuromodulators: Handbook of Receptors and Biological Effects. 2nd ed, Weinheim (Germany), Ed. WILEY-VCH Verlag GmbH \& Co. KGaA, 2006; 3: 46 - 143.

17. Cooper JR, Bloom FE and Roth RH. The Biochemical Basis of Neuropharmacology. 8nd ed, Oxford University Press, Inc, 2003; 85 - 356.

18. Hernandes MS and Troncone LRP. Glycine as a neurotransmitter in the forebrain: a short review. J Neural Transm. 2009; 116: 1551-60.

19. Goridis $\mathrm{C}$ and Rohrer H. Specification of catecholaminergic and serotonergic neurons Nat Rev Neurosci. 2002, 3: 53141.

20. Burnstock G. Purinergic signaling: past, present and future. Braz J Med Biol Res. 2009, 42: 3-8.

21. Leonelli M, Torrão AS and Britto LRG. Unconventional neurotransmitters, neurodegeneration and neuroprotection. Braz J Med Biol Res.

22. Snyder SH. Nitric oxide: first in a new class of transmitters. Science 1992, 257: 494-496.

23. Piomelli $D$. The molecular logic of endocannabinoid sinalling. Nat Rev Neurosci. 2003, 4: 873-884.

24. V Di Marzo, Melck D, Bisogno $T$ and De Petrocellis $L$. Endocannabinoids: endogenous cannabionoid receptor ligands with neuromodulatory action. Trends Neurosci. 1998, 21: $521-28$

25. Wilson RI and Nicoll RA. Endocannabinoid signaling in the brain. Science. 2002, 296: 678-82.

26. Maquire-Zeiss KA. alpha-Synuclein: a therapeutic target for Parkinson's disease? Pharmacol Res. 2008, 58 (5-6): 27180.

27. Moult PR. Neuronal glutamate and GABAA receptor function in health and disease. Biochem Soc Trans. 2009; 37: 131722.

28. Keltikangas-Järvinen L, Salo J. Dopamine and serotonin systems modify environmental effects on human behavior: A review. Scand J Psychol. 2009; 50(6): 574-82.

29. Augustine GJ, Eckert R. Divalent cations differentially support transmitter release at the squid giant synapse. J Physiol. 1984; 346: 257-71.

30. Miledi R. Lanthanum ions abolish the "calcium response" of nerve terminals. Nature. 1971; 229(5284): 410-411.

31. Meinrenken CJ, Borst JG, Sakmann B. Local routes revisited: the space and time dependence of the $\mathrm{Ca} 2+$ signal for phasic transmitter release at the rat calyx of Held. J Physiol. 2003; 547: 665-89.

32. Heuser JE, Reese TS. Structural changes after transmitter release at the frog neuromuscular junction. J Cell Biol. 1981; 88(3): 564-580.

33. Ceccarelli B, Hurlbut WP, Mauro A. Depletion of vesicles from frog neuromuscular junctions by prolonged tetanic stimulation. J Cell Biol. 1972; 54: 30-38.

34. Ceccarelli B, Hurlbut WP, Mauro A. Turnover of transmitter and synaptic vesicles at the frog neuromuscular junction. J. Cell Biol. 1973; 57: 499-524.

35. Heuser JE, Reese TS. Evidence for recycling of synaptic vesicle membrane during transmitter release at the frog neuromuscular junction. J. Cell Biol. 1973; 57: 315-344.

36. Goda Y, Südhof TC. Calcium regulation of neurotransmitter release: reliably unreliable. Curr. Opin. Cell Biol. 1997; 9:513518
37. Südhof TC. The synaptic vesicle cycle Annu. Rev. Neurosci 2004; 27: 509-47

38. Masson J, Sagné C, Hamon M, El Mestikawy S. Neurotransmitter transporters in the central nervous system. Pharmacol Rev. 1999; 51(3): 439-464.

39. Fremeau RT Jr, Voglmaier S, Seal RP, Edwards RH. VGLUTs define subsets of excitatory neurons and suggest novel roles for glutamate. Trends Neurosci. 2004; 27(2): 98-103.

40. Becherer U, Rettig J. Vesicle pools, docking, priming, and release Cell Tissue Res. 2006; 326(2): 393-407.

41. Wojcik SM, Brose N. Regulation of membrane fusion in synaptic excitation-secretion coupling: speed and accuracy matter. Neuron. 2007 5; 55(1): 11-24.

42. Katz B. 1969. The Release of Neural Transmitter Substances. In: Thomas Koenig JH, Ikeda K. editors. Synaptic vesicles have two distinct recycling pathways. Springfield, IL. J Cell Biol 1996. p. 797-808.

43. Pyle JL, Kavalali E, Piedras-Renteria ES, Tsien RW. Rapid reuse of readily releasable pool vesicles at hippocampal synapses. Neuron. 2000; 28: 221-31.

44. Richards DA, Guatimosim C, Betz WJ. Two endocytic recycling routes selectively fill two vesicle pools in frog motor nerve terminals. Neuron. 2000; 27: 551-9.

45. Benfenati F, Greengard P, Brunner J, Bahler M. Electrostatic and hydrophobic interactions of synapsin I and synapsin I fragments with phospholipid bilayers. J Cell Biol. 1989; 108: 1851-62.

46. Fremeau RT Jr, Burman J, Qureshi T, Tran CH, Proctor J, et al. The identification of vesicular glutamate transporter 3 suggests novel modes of signaling by glutamate. Proc. Natl. Acad. Sci. USA 2002; 99:14488-93.

47. Gras C, Herzog E, Bellenchi GC, Bernard V, Ravassard P, et al. A third vesicular glutamate transporter expressed by cholinergic and serotoninergic neurons. J Neurosci. 2002; 22: $5442-51$.

48. Erickson JD, Eiden LE, Hoffman BJ. Expression cloning of a reserpine-sensitive vesicular monoamine transporter. Proc. Natl. Acad. Sci. USA 1992; 89: 10993-7.

49. Liu Y, Peter D, Roghani A, Schuldiner S, Prive GG, et al. A cDNA that suppresses MPP+ toxicity encodes a vesicular amine transporter. Cell. 1992; 70: 539-51.

50. McIntire SL, Reimer RJ, Schuske K, Edwards RH, Jorgensen EM. Identification and characterization of the vesicular GABA transporter. Nature 1997; 389: 870-6.

51. Sagne C, El Mestikawy S, IsambertMF, Hamon M, Henry JP, et al. Cloning of a functional vesicular GABA and glycine transporter by screening of genome databases. FEBS Lett. 1997; 417: 177-83.

52. Varoqui H, Diebler MF, Meunier FM, Rand JB, Usdin TB, et al. Cloning and expression of the vesamicol binding protein from the marine ray Torpedo. Homology with the putative vesicular acetylcholine transporter UNC-17 from Caenorhabditis elegans. FEBS Lett. 1994; 342: 97-102

53. Bekkers JM, Richerson GB, Stevens CF. Origin of variability in quantal size in cultured hippocampal neurons and hippocampal slices. Proc. Natl. Acad. Sci. USA 1990; 87: 5359-62.

54. Bruns D, Riedel D, Klingauf J, Jahn R. Quantal release of serotonin. Neuron. 2000; 28: 205-20.

55. Söllner T, Whiteheart SW, Brunner M, Erdjument- Bromage H, Geromanos S, et al. SNAP receptors implicated in vesicle targeting and fusion. Nature 1993; 362: 318-24. 
56. Chen YA, Scheller RH. SNARE mediated membrane fusion. Nat Rev Mol Cell Biol. 2001; 2: 98-106.

57. Jahn R, Lang T, Südhof TC. Membrane fusion. Cell. 2003; 112: 519-33.

58. Sugimori M, Tong C, Fukuda M, Moreira JE, Kojima T, Mikoshiba $\mathrm{K}$ and Llinás, R. Presynaptic injection of syntaxin specific antibodies block transmission in the squid giant synapse. Neuroscience 1998; 86: 39-51.

59. McMahon HT, Missler M, Li C, Südhof TC. Complexins: cytosolic proteins that regulate SNAP receptor function. Cell. 1995; 83: 111-9.

60. Fukuda M, Moreira JE, Liu V, Sugimori M, Mikoshiba K and Llinás R. Role of the conserved WHXL motif in the $\mathrm{C}$ terminus of synaptotagmin in synaptic vesicle docking. Proc. Natl. Acad. Sci. USA 2000; 97:14715-19.

61. Fukuda M, Moreira JE, Lewis FMT, Sugimori M, Niinobe $M$, Mikoshiba $\mathrm{K}$ and Llinás RR. Role of the C2B domain of synaptotagmin in vesicular release and recycling as determined by specific antibody injection into the squid giant synapse preterminal. Proc. Natl. Acad. Sci. USA 1995; 92:10703-7.

62. Mikoshiba K, Fukuda M, Moreira JE, Lewis FMT, Sugimori M, Niinobe $M$ and Llinás RR. Role of the C2A domain of synaptotagmin in transmitter release as determined by specific antibody injection into the squid giant synapse preterminal. Proc.Natl.Acad. Sci. USA 1995; 92:10708-12.

63. Chapman ER. How does synaptotagmin trigger neurotransmitter release? Annu Rev Biochem. 2008; 77: 615-41.

64. Dulubova I, Sugita S, Hill S, Hosaka M, Fernandez I, et al. A conformational switch in syntaxin during exocytosis. EMBO J 1999; 18: 4372-82.

65. Schoch S, Deak F, Konigstorfer A, Mozhayeva M, Sara Y, et al. SNARE function analyzed in synaptobrevin/VAMP knockout mice. Science. 2001; 294: 1117-22.

66. Edelmann L, Hanson PI, Chapman ER, Jahn R. Synaptobrevin binding to synaptophysin: a potential mechanism for controlling the exocytotic fusion machine. EMBO J. 1995; 14: 22431.

67. Becher A, Drenckhahn A, Pahner I, Margittai M, Jahn R, AhnertHilger G. The synaptophysin-synaptobrevin complex: a hallmark of synaptic vesicle maturation. J. Neurosci 1999; 19: 1922-31.

68. Malsam J, Kreye S, Sçllner TH. Membrane fusion: SNAREs and regulation. Cell Mol Life Sci. 2008; 65: 2814 - 32.

69. Gaidarov I, Keen JH. Phosphoinositide- AP-2 interactions required for targeting to plasma membrane clathrin-coated pits. J Cell Biol. 1999; 146: 755-64.

70. Takei K, Slepnev VI, Haucke V, De Camilli P. Functional partnership between amphiphysin and dynamin in clathrin-mediated endocytosis. Nat Cell Biol. 1999; 1: 33-39.

71. Schlossman DM, Schmid SL, Braell WA, Rothman JE. An enzyme that removes clathrin coats: purification of an uncoating ATPase. J Cell Biol. 1984; 99: 723-33.

72. Ahle S, Ungewickell E. Auxilin, a newly identified clathrinassociated protein in coated vesicles from bovine brain. $\mathrm{J}$ Cell Biol. 1990; 111: 19-29.

73. Daly C, Sugimori M, Moreira JE, Ziff EB and Llinás R. Synaptophysin regulates Clathrin-Independent (Kiss-andRun) synaptic vesicle endocytosis. Proc.Natl.Acad.Sci.USA 2000; 97:6120-5.

74. Morgan JR., Augustine GJ, Lafer EM. Synaptic Vesicle Endocytosis The Races, Places, and Molecular Faces NeuroMolecular Medicine, 2002; 2: 101-14.
75. He L, Wu LG, The debate on the kiss-and-run fusion at synapses, Trends Neurosci. 2007; 30(9): 447-55.

76. Holtmaat A, Svoboda K. Experience-dependent structural synaptic plasticity in the mammalian brain. Nat Rev Neurosci. 2009; 10: 647-58.

77. Bennett MR. The early history of the synapse: From Plato to Sherrington. Brain Res Bull. Brain Res Bull. 1999; 50(2): 95118.

78. Nimchinsky EA, Sabatini BL, Svoboda K. Structure and function of dendritic spines. Ann Rev Physiol. 2002; 64:313-53.

79. Dunaevsky A, Tashiro A, Majewska A, Mason C, Yuste R. Developmental regulation of spine motility in the mammalian central nervous system. Proc. Natl. Acad. Sci. USA 1999; 96: 13438-43.

80. Ziv NE, Smith SJ. Evidence for a role of dendritic filopodia in synaptogenesis and spine formation. Neuron. 1996; 17: 91102.

81. Fiala JC, Spacek J, Harris KM. Dendritic spine pathology: cause or consequence of neurological disorders? Brain Res Brain Res Rev. 2002; 39: 29-54.

82. Tsai J, Grutzendler J, Duff K, Gan WB. 2004. Fibrillar amyloid deposition leads to local synaptic abnormalities and breakage of neuronal branches. Nat Neurosci. 7:1181-3.

83. Zhang S, Boyd J, Delaney K, Murphy TH. Rapid reversible changes in dendritic spine structure in vivo gated by the degree of ischemia. J Neurosci. 2005; 25: 5333-5338.

84. Zuo Y, Lin A, Chang P, Gan WB. Development of long-term dendritic spine stability in diverse regions of cerebral cortex. Neuron. 2005; 46: 181-9.

85. Harris KM, Kater SB. Dendritic spines: cellular specializations imparting both stability and flexibility to synaptic function. Ann Rev Neurosci. 1994; 17: 341-71.

86. Rasia-Filho AA, Brusco J, Moreira JE. Spine plasticity in the rat medial amygdala. In: Baylog LR editor. Dendritic Spines: Biochemistry, Modeling and Properties. New York: Nova Science Publishers; 2009. p. 67-90.

87. Okabe S. Molecular anatomy of the postsynaptic density. Mol Cell Neurosci. 2007; 34: 503-18.

88. Kim E, Sheng M. PDZ domain proteins of synapses. Nat Rev Neurosci. 2004; 5: 771-81.

89. Schallert T, Leasure JL, Kolb B. Experienceassociated structural events, subependymal cellular proliferative activity, and functional recovery after injury to the central nervous system. J Cereb Blood Flow Metab. 2000; 20:1513-28.

90. Dancause, N. et al. Extensive cortical rewiring after brain injury. J Neurosci. 2005; 25: 10167-79.

91. Brown CE, Li P, Boyd JD, Delaney KR, Murphy TH. Extensive turnover of dendritic spines and vascular remodeling in cortical tissues recovering from stroke. J Neurosci. 2007; 27: 4101-4109.

92. Ramakers GJ. Rho proteins, mental retardation and the cellular basis of cognition. Trends Neurosci. 2002; 25: 191-9.

93. Funke L, Dakoji S, Bredt DS. Membrane-associated guanylate kinases regulate adhesion and plasticity at cell junctions. Ann Rev Biochem. 2005; 74: 219-45.

94. Aarts M, Liu Y, Liu L, Besshoh S, Arundine M, Gurd et al. Treatment of ischemic brain damage by perturbing NMDA receptor-PSD-95 protein interactions. Science. 2002; 298: 846-850.

95. Gardoni F, Picconi B, Ghiglieri V, Polli F, Bagetta V, Bernardi G, et al. A critical interaction between NR2B and MAGUK in LDOPA induced dyskinesia. J Neurosci. 2006; 26: 2914-22. 
96. Gardoni F. MAGUK proteins: New targets for pharmacological intervention in the glutamatergic synapse. Eur J Pharmacol. 2008; 585: 147-52.

97. Sattler R, Tymianski M. Molecular mechanisms of glutamate receptormediated excitotoxic neuronal cell death. Mol Neurobiol. 2001; 24: 107-29.

98. Ishii M, Kurachi Y. Physiological actions of regulators of Gprotein signaling (RGS) proteins. Life Sci.74 (2003) 163-71.

99. Conn P M, Blum J J,. Gonadotropin-releasing hormone stimulation of luteinizing hormone release: A ligand-receptor-effector model. Proc Natl Acad Sci U S A. 1982 December; 79: 7307-11.

100. Maggio R, Vogel Z, Wess J. Coexpression studies with mutant muscarinic/adrenergic receptors provide evidence for intermolecular "cross-talk" between G-protein-linked receptors. Proc Natl Acad Sci U S A. 1993 April 1; 90(7): 3103-7.

101. Gilman AG. G Proteins and Regulation of Adenylyl Cyclase. Nobel Lecture, December 8, 1994.

102. Rodbell M. Signal Transduction: Evolution of an Idea. Nobel Lecture, December 8, 1994.

103. Oro C, Qian H, Thomas WG. Type 1 angiotensin receptor pharmacology: Signaling beyond G proteins. Pharmacol Ther. 2007; 113: 210-26.

104. Nürnberg B, Tögel W, Krause G, Storm R, Breitweg-Lehmann E, Schunack W. Non-peptide G-protein activators as promising tools in cell biology and potential drug leads. Eur J Med Chem. 1999; 34: 5?30.

105. Spiegelberg BD, Hamm HE. Roles of G-protein-coupled receptor signaling in cancer biology and gene transcription. Genetics \& Development 2007; 17: 40-4.

106. Catapano LA, Manji HK. G protein-coupled receptors in major psychiatric disorders. Biochimica et Biophysica Acta 2007; 1768: $976-93$.
107. Dalrymple MB, Pfleger KDG, Eidne KA. G protein-coupled receptor dimers: Functional consequences, disease states and drug targets. Pharmacol Ther. 2008; 118: 359-371.

108. Burns A and Iliffe S. Alzheimer's disease. Clinical Review. 2009; 338: 476-1.

109. Younkin SG. The role of A?42 in Alzheimer's disease. J Physiol. 1998; 92: 298-292.

110. LaFerla FM, Green KN and Oddo S. Intracellular amyloid-? in Alzheimer's disease. Nat Rev Neurosci. 2007; 8: 499-509.

111. Herman Moreno, Eunah Yu, Gustavo Pigino, Alejandro I.Hernandez, Natalia Kime, Jorge E. Moreira, Mutsuyuki Sugimori, and Rodolfo R. Llinas. Synaptic transmission block by presynaptic injection of oligomeric amyloid beta. Proc. Natl. Acad. Sci. USA 2009; 106 (14): 5901-6.

112. Andersen JK. Does neuronal loss in Parkinson's disease involve programmed cell death? Bioessays. 2001; 23: 6406.

113. Braak H, Del Tredici K, Rub U, de Vos RA, Jansen Steur EM and Braak E. Staging of brain pathology related to sporadic Parkinson's disease. Neurobiol Aging. 2003, 24(2): 197-211.

114. Morfini G, Pigino G, Opalach K, Serulle Y, Moreira JE, Sugimori M, Llinás R and Brady ST. 1-Methyl-4-phenylpyridinium affects fast axonal transport by activation of caspasse and Protein Kinase C. Proc. Natl. Acad. Sci. USA 2007; 104: $2442-$ 7.

115. Serulle Y, Morfini G, Pigino G, Moreira JE, Opalach K, Sugimori ST, Brady ST and Llinás R. 1-Methyl-4-phenylpyridinium induces synaptic dysfunction through a pathway involving caspase and PKC (delta) enzimatic activities. Proc. Natl. Acad. Sci. USA 2007, 104: 2437-41.

116. Marsal J, Ruiz-Montacell B, Blasi J, Moreira,JE, Contreras D, Sugimori $\mathrm{M}$ and Llinás, $\mathrm{R}$. Block of transmitter release by botulinum $\mathrm{C} 1$ action on syntaxin at the squid giant synapse. Proc. Natl. Acad. Sci. USA 1997; 94:14871-6. 